Titulo do Trabalho

\title{
ANÁLISE DE CONFLITO ENTRE LEGISLAÇÃO AMBIENTAL E USO E OCUPAÇÃO DO SOLO EM ÁREAS DE PRESERVAÇÃO PERMANENTE
}

Nome do Autor (a) Principal

\section{Ana Clara Barros}

Nome (s) do Coautor (a) (s)

Mikael Timóteo Rodrigues; Felipe de Souza Nogueira Tagliarini

Nome (s) do Orientador (a) (s)

Yara Manfrin Garcia

Instituição ou Empresa

Universidade Estadual Paulista "Julio de Mesquita Filho" - UNESP/FCA, Botucatu

E-mail de contato

anaclara_inha@hotmail.com

Palavras-chave

Microbacia Hidrográfica.Código Florestal. Sistema de Informação Geográfica.

INTRODUÇÃO

Segundo Piroli et al. (2002) a escolha de uma microbacia como local de investigação é por esta ser uma unidade de estudo onde se tem diferentes características que vão desde regiões altas, onde normalmente estão localizadas as nascentes - dos riachos e córregos -, áreas das encostas onde as águas correm com 
maior velocidade, e finalmente, as áreas de baixadas onde normalmente são observadas as consequências do manejo inadequado feito nas altitudes mais elevadas.

O conjunto dos aspectos físico-naturais das bacias hidrográficas produz consequências diretas e indiretas sobre o seu sistema hídrico. A qualidade da água de mananciais que a compõem está relacionada com a quantidade de chuva, uso da terra e com o grau de controle sobre as fontes de poluição. As alterações na qualidade da água estão diretamente relacionadas com as alterações que ocorrem na bacia hidrográfica, como vegetação e solo (SANTOS; PEREIRA FILHO, 2010).

No Brasil, a unidade física adotada na legislação para o gerenciamento de recursos hídricos é a de bacia hidrográfica que constitui um princípio básico para a implementação da gestão dos recursos hídricos, sendo que tal denominação também é utilizada em outros países (GARCIA, 2011).

A legislação ambiental brasileira pode ser considerada ampla, entretanto, a deficiência em meios e materiais, dentre outros fatores, para apurar com rigor as agressões ao meio ambiente, tem dificultado sua aplicação (CRESTANA; TOLEDO FILHO; CAMPOS, 1993).

E é na legislação ambiental brasileira que foram criadas em 1965, as Áreas de Preservação Permanente (APPs) que tem como finalidade proteger o ambiente natural, não permitindo nelas alteração do uso da terra.

Segundo Magalhães e Ferreira (2000), um dos grandes desafios para a conservação ambiental é a preservação e recuperação de áreas naturais consideradas estratégicas, dentre elas, destacam-se as Áreas de Preservação Permanente dentro de uma microbacia, pois são responsáveis pela manutenção, preservação e conservação dos ecossistemas existentes.

A importante função das APPs, no que determina a lei, pode ser interpretada como a função fundamental de garantir um arranjo espacial básico da paisagem para a manutenção dos ciclos hídricos, geológicos, do solo, da biodiversidade. Tal arranjo constitui um dos pilares para a existência de uma possível sociedade sustentável. No que diz respeito às suas funções e definições espaciais, se conformam em elementos 
do espaço integradores de diversas áreas do conhecimento e no contexto político, se conforma na materialização do conceito de "Desenvolvimento Sustentável" (SILVA; BRAGA; FONSECA, 2010).

Atualmente, a Lei $\mathrm{n}^{\circ} 12.727$ de 17 de outubro de 2012, conhecida como Lei Florestal, em seu Art. $4^{\circ}$ considera-se Áreas de Preservação Permanente, em zonas rurais ou urbanas e estabelece para os efeitos desta Lei (BRASIL, 2012):

I - as faixas marginais de qualquer curso d'água natural perene e intermitente, excluídos os efêmeros, desde a borda da calha do leito regular, em largura mínima de:

a) 30 (trinta) metros, para os cursos d'água de menos de 10 (dez) metros de largura;

b) 50 (cinquenta) metros, para os cursos d'água que tenham de 10 (dez) a 50 (cinquenta) metros de largura;

c) 100 (cem) metros, para os cursos d'água que tenham de 50 (cinquenta)

a 200 (duzentos) metros de largura;

d) 200 (duzentos) metros, para os cursos d'água que tenham de 200

(duzentos) a 600 (seiscentos) metros de largura;

e) 500 (quinhentos) metros, para os cursos d'água que tenham largura superior a 600 (seiscentos) metros; (BRASIL, 2012).

Frente a isso, percebe-se que nos estudos de bacias hidrográficas, torna-se cada vez mais necessária a análise das Áreas de Preservação Permanente que segundo Boin (2005), a existência de conflitos entre uso e ocupação e o descumprimento da legislação nessas áreas coloca em risco a quantidade e qualidade dos recursos hídricos, devido à dinâmica fluvial e ao escoamento superficial da água.

O presente trabalho buscou empregar metodologias e a utilização de geotecnologias para o mapeamento dos conflitos ambientais em APPs, contribuindo assim para o processo de gestão e conservação dos recursos naturais. 


\section{OBJETIVO GERAL}

O objetivo principal deste trabalho foi oferecer subsídios para o disciplinamento do uso e da ocupação do solo em Áreas de Preservação Permanente na microbacia hidrográfica do córrego Monte Belo, Botucatu (SP).

\section{OBJETIVOS ESPECÍFICOS}

Os objetivos específicos do presente estudo é contribuir para o gerenciamento dos recursos hídricos através da recuperação, conservação e preservação ambiental da microbacia tendo como suporte a utilização da geotecnologias e da legislação ambiental brasileira.

\section{METODOLOGIA}

Para atingir o objetivo proposto neste trabalho, foi necessária a criação de um banco de dados georreferenciado com arquivos e imagens representando planos de informação de interesse a partir dos mapas de rede de drenagem e uso e ocupação do solo. O SIG utilizado para a criação do banco de dados georreferenciado, tratamento, análise dos dados espaciais e visualização de imagem foi o IDRISI SELVA.

Para o apoio cartográfico, utilizou-se a carta planialtimétrica em formato digital, editada pelo IBGE (1973) referente a folha de folha de Botucatu (SF-22-R-IV3), sendo o sistema de referência o Córrego Alegre (antigo datum planimétrico brasileiro), em escala 1:50.000 com equidistância das curvas de nível de 20 metros onde obteve-se os pontos de controle (coordenadas) para o georreferenciamento e a altimetria para digitalização do limite da bacia hidrográfica.

A imagem de satélite utilizada foi do Landsat - 5, sensor TM (Thematic Mapper), de 19 de setembro de 2011, da órbita 220, ponto 76 , com resolução espacial 
de 30 x 30 metros, operando em sete bandas espectrais das quais, para este trabalho, utilizaram-se três bandas (3, 4 e 5), pois estas apresentam uma melhor visualização na discriminação dos alvos. As imagens foram obtidas no catálogo de imagens do Instituto Nacional de Pesquisas Espaciais.

A primeira etapa consistiu no georreferenciamento da carta planialtimétrica do IBGE e posteriormente, com base nessa, das bandas 3, 4 e 5 da imagem de satélite, ambas foram realizadas no IDRISI, menu Reformat/Resample. Com as bandas das imagens georreferenciadas, foi realizado o processo de composição da imagem RGB (Red, Green, Blue), respectivamente as bandas 5, 4 e 3, utilizando-se da função Composite do menu Display do IDRISI e no menu Reformat/Window, o recorte da área.

Em seguida, no software CartaLinx começou-se a delimitar os elementos (coverages) - limite e rede de drenagem pela carta topográfica e delimitação dos usos do solo na composição - sendo que, para o limite e os usos foram criados polígonos, enquanto que, para a rede de drenagem, linhas. Uma coverage representa uma coleção de feições geográficas e seus atributos (HAGAN; EASTMAN; AUBLE, 1998).

No IDRISI, definiram-se as APPs ao longo dos cursos d'água e ao redor das nascentes do córrego Barra Seca. Os buffers foram criados no menu GIS Analysis, ferramenta Distance Operators - BUFFER. Para isso, foi necessário repetir esse passo duas vezes, sendo uma para os cursos d'água e o outro para a nascente.

Assim, proporcionou-se a criação de um buffer de raio de 50 metros circulando as áreas das nascentes e um buffer de 30 metros de cada lado da margem na drenagem ao longo do leito do córrego (medidas estas estipuladas pela Lei Florestal $n^{\circ} 12.727$, sendo que a largura das redes de drenagens presente na área estudada são inferiores a 10 metros).

Para identificar as áreas de conflitos de uso do solo em APPs, utilizou-se a álgebra de mapas realizando uma sobreposição do mapa de uso e ocupação do solo com o mapa das APPs. Os procedimentos foram executados no IDRISI utilizando-se a ferramenta Mathematical Operators - OVERLAY do menu GIS Analysis e 
selecionou-se a opção matemática First x Second, operação essa que pode também ser denominada de sobreposição.

Após a sobreposição desses mapas, as áreas de ocorrência dos conflitos de acordo com as classes de uso foram devidamente quantificadas, executando as funções de cálculo de área, pela ferramenta Area do menu Database Query, pertencente ao módulo Analysis do IDRISI. Foram consideradas sob uso conflitante as áreas cultivadas e ocupadas com outros fins presentes nas APPs das nascentes e cursos d'água.

\section{RESULTADO (S)}

A microbacia do Córrego Monte Belo está situada na porção norte do município de Botucatu com uma área de 1697,22ha, situando-se geograficamente entre as coordenadas: latitude $22^{\circ} 45^{\prime}$ a $22^{\circ} 48^{\prime} \mathrm{S}$ e longitudes $48^{\circ} 15^{\prime}$ a $48^{\circ} 21^{\prime} \mathrm{W}$ Gr. (Figura 1).

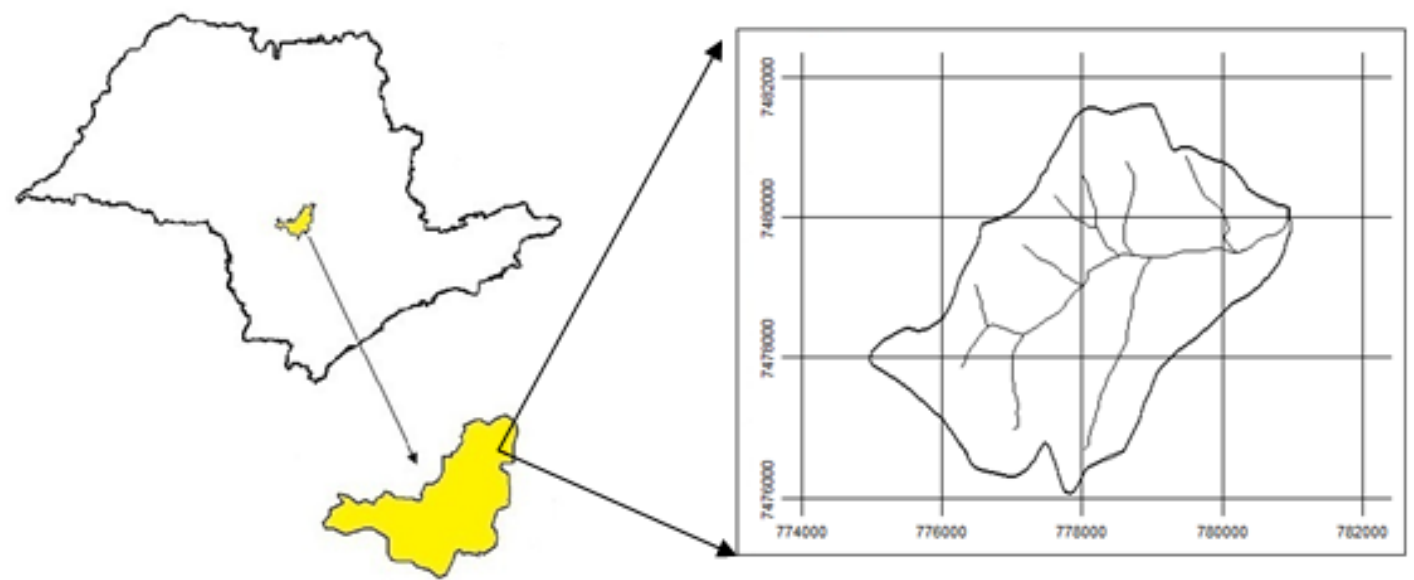

Figura 1 - Localização da microbacia do Córrego Monte Belo no estado de São Paulo

Como resultado do estudo, pode-se verificar a identificação de três classes de uso: reflorestamento, mata ciliar e solo exposto. O Sistema de Informação Geográfica mostrou-se bastante eficiente na identificação, no mapeamento e na determinação 
das ocupações do solo, minimizando a complexidade e o grau de especificidade na quantificação dessas áreas.

A área total da microbacia hidrográfica do córrego Monte Belo é de 1697,22 hectares que estão sendo ocupados 818,62 ha por reflorestamento, 804,12 ha de mata ciliar e 74,48ha de solo exposto.

Com base na legislação vigente, Lei Florestal $n^{0} 12.727$ foram mapeadas as APPs para as nascentes da bacia de estudo em um raio de 50 metros e para os cursos d'água em 30 metros de cada lado, esta última metragem, decorrente de que os rios inseridos na bacia são estreitos, não ultrapassando 10 metros de largura.

Além da existência dessas faixas de preservação permanente, é essencial que esteja coberta por vegetação. As mata ciliares são importantes pois reduzem o transporte de material nos cursos d'água, o assoreamento em suas margens, minimizam os processos erosivos, auxiliam na manutenção e preservação da biodiversidade, entre outros (GARCIA, 2014).

A hidrografia da área permitiu estabelecer que as APPs estão representadas com 111,16ha.

Por meio da sobreposição do mapa de uso e ocupação do solo e o de APPs foi gerado o mapa de conflito de uso em APPs que contribui como ponto de partida para a identificação de áreas de uso adequado e de parte dos problemas ambientais existentes na bacia, como por exemplo as áreas de conflito.

Os conflitos de uso são determinados pelas ocupações inadequadas do solo dentro de Áreas de Preservação Permanente (Figura 2). 


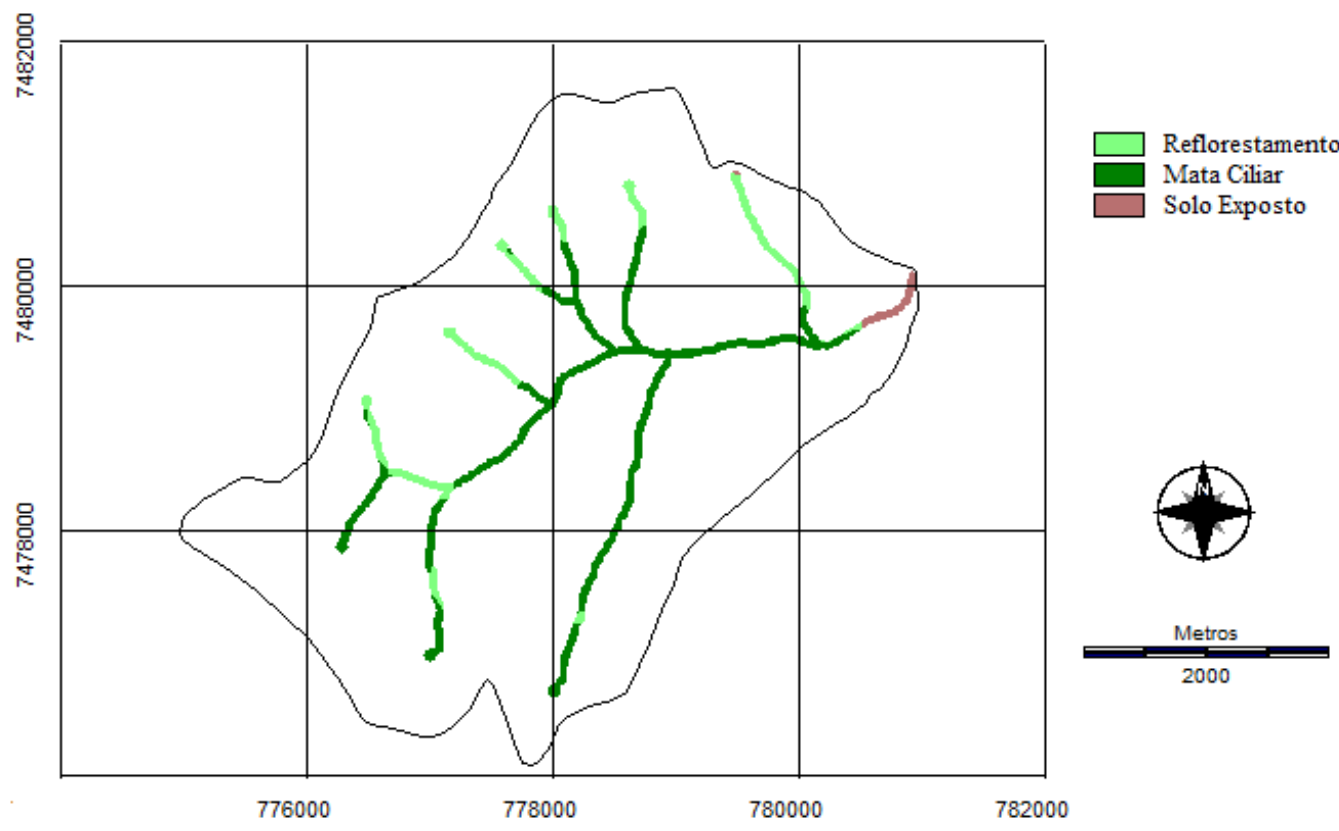

Figura 2 - Conflitos em Áreas de Preservação Permanente na microbacia

Quanto as áreas de conflitos, estas mostram que 36,39ha estão sendo usadas para outros fins o que representa $32,73 \%$ da APPs da microbacia do córrego Monte Belo. Na Tabela 1 estão apresentadas as classes de uso do solo e os conflitos nas Áreas de Preservação Permanente.

Tabela 1 - Áreas de Preservação Permanente e de conflitos em APPs (ha e \%)

\begin{tabular}{ccccc}
\hline $\begin{array}{c}\text { Classes de Uso } \\
\text { do Solo }\end{array}$ & \multicolumn{2}{c}{ APPs } & \multicolumn{2}{c}{ Conflitos } \\
& (ha) & $\%$ & (ha) & $\%$ \\
\hline Reflorestamento & 32,04 & 28,82 & 32,04 & 88,04 \\
Mata Ciliar & 74,77 & 67,27 & - & - \\
Solo Exposto & 4,35 & 3,91 & 4,35 & 11,96 \\
\hline Total & 111,16 & 100 & 36,39 & 100 \\
\hline
\end{tabular}

Desta forma, para concluir, quanto a situação da microbacia hidrográfica do córrego Monte Belo, enfatiza-se a necessidade de estudos para que as situações 
apresentadas anteriormente sejam alteradas por meio de práticas de preservação e conservação do meio ambiente de maneira a integrar no contexto jurídico.

\section{CONSIDERAÇÕES FINAIS}

Como conclusão do presente estudo destaca-se a importância da geotecnologia para a preservação do meio ambiente. Através da utilização de Sistema de Informação Geográfica e Sensoriamento Remoto foi possível o mapeamento do uso e ocupação do solo e identificar as áreas de conflito nas Áreas de Preservação Permanente.

Constatou-se, que as Áreas de Preservação Permanente $(111,16$ ha) da bacia hidrográfica estudada não estão totalmente preservadas conforme legislação pertinente - Lei $\mathrm{n}^{\circ} 12.727$, de 17 de outubro de 2012 - e que estas vêm sendo ocupadas reflorestamento (32,04ha) e solo exposto $(4,35 \mathrm{ha})$.

\section{REFERÊNCIAS}

BRASIL. Lei n ${ }^{0} 12.727$, de 17 de outubro de 2012. Altera a Lei no 12.651, de 25 de maio de 2012, que dispõe sobre a proteção da vegetação nativa; altera as Leis nos6.938, de 31 de agosto de 1981, 9.393, de 19 de dezembro de 1996, e 11.428, de 22 de dezembro de 2006; e revoga as Leis nos 4.771, de 15 de setembro de 1965, e 7.754, de 14 de abril de 1989, a Medida Provisória no 2.166-67, de 24 de agosto de 2001, o item 22 do inciso II do art. 167 da Lei no 6.015, de 31 de dezembro de 1973, e o $\S$ 20 do art. 4o da Lei no 12.651, de 25 de maio de 2012. Diário Oficial da União, Brasília, DF, 18 out. 2012. 2012. Disponível em:< http://www.planalto.gov.br/ccivil_03/_Ato2011-2014/2012/Lei/L12727.htm> Acesso em: 13 jul. 2014.

BOIN, M. N. Áreas de Preservação Permanente: Uma visão prática. Manual Prático da promotoria de Justiça do Meio Ambiente. 1 ed. São Paulo: Imprensa Oficial do Estado de São Paulo, v.2. 2005.

CRESTANA, M. S. M.; TOLEDO FILHO, D. V.; CAMPOS, J. B. Florestas: sistemas de recuperação com essências nativas. Campinas: CATI, 1993.60p.

GARCIA, Y. M. Conflitos de uso do solo em APPs na bacia hidrográfica do córrego Barra Seca (Pederneiras/SP) em função da legislação ambiental.. Dissertação (Mestrado em Agronomia/Energia na Agricultura) - Faculdade de Ciências Agronômicas, Universidade Estadual Paulista. Botucatu-SP. UNESP. 2014.

GARCIA, Y. M. Aplicação do Código Florestal como Subsídio para o Planejamento Ambiental na Bacia Hidrográfica do Córrego do Palmitalzinho - Regente Feijó - São Paulo. Trabalho de 
conclusão (Bacharelado - Geografia) - Universidade Estadual Paulista, Faculdade de Ciências e Tecnologia - Presidente Prudente: [s.n], 2011, 145 f.

HAGAN, J.E; EASTMAN, J. R.; AUBLE, J. CartaLinx. The Spatial Data Builder. User's Guide. Version 1.0. Clark Labs. Clark University. 201p. 1998.

INPE. Instituto Nacional de Pesquisas Espaciais - Divisão de Geração de Imagens (DGI-INPE). Catálogo de Imagens. Disponível em:<http://www.dgi.inpe.br/>. Acesso em: 05 jun. 2014.

IBGE. Instituto Brasileiro de Geografia e Estatística. Carta topográfica. Serviço gráfico do IBGE, 1973. Escala 1:50.000.

MAGALHÃES, C. S.; FERREIRA, M. A. Áreas de preservação permanente em uma microbacia. Informe Agropecuário, Belo Horizonte, v. 1, n. 207, p. 33-39, nov./dez. 2000.

PIROLI, E. L.; BECKER, E. L. S.; BOLFE, E. L.; PEREIRA, R. S. Análise do uso da terra na microbacia do Arroio do Meio - Santa Maria - RS, por Sistema de Informações Geográficas e imagem de satélite. Cienc. Rural [online]. 2002, vol.32, n.3, 2002, p. 407-413.

SANTOS, F. C. dos; PEREIRA FILHO, W. Sensoriamento remoto aplicado aos estudos de ambientes aquáticos continentais. In: Reflexões sobre a Geografia do Rio Grande do Sul: Temas em Debate. Santa Maria: UFSM, 2010. p. 209- 222. Disponível em:

<http://w3.ufsm.br/ppggeo/files/ebook01/Art.12.pdf>. Acesso em: 20 jul. 2014.

SILVA, S. H. L. da.; BRAGA, F. A.; FONSECA, A. R. Análise de conflito entre legislação e uso da terra no município de Itabira - MG. Caminhos de Geografia. Uberlândia v. 11, n. 34 jul/2010 p. 131 - 144. 